\title{
Commentary
}

\section{Global public good and universal health coverage: conceptual and practical concerns in the context of COVID-19}

\author{
Rajasekharan K. Nayar* \\ Global Institute of Public Health, Ananthapuri Hospitals and Research Institute, Thiruvananthapuram, Kerala, India
}

Received: 26 March 2021

Revised: 28 April 2021

Accepted: 29 April 2021

\section{*Correspondence:}

Dr. Rajasekharan K. Nayar,

E-mail: krnayar@gmail.com

Copyright: (c) the author(s), publisher and licensee Medip Academy. This is an open-access article distributed under the terms of the Creative Commons Attribution Non-Commercial License, which permits unrestricted non-commercial use, distribution, and reproduction in any medium, provided the original work is properly cited.

The notion of public good has been reclaimed in recent times due to the pandemic as in many countries including the United States, the existing infrastructural, strategic and investment limitations have been realized. ${ }^{1}$ There is need for a debate on the notion of global public good especially with respect to health and to bring out the incommensurability of the notion. ${ }^{2}$ Along with these realizations and reclamations, issues related to the three A's- accessibility, availability and affordability of health car have also been raised as a part of universal health coverage (UHC). The three A's have become more relevant in the context of the pandemic. However, the ideological underpinnings of such conceptual reclamations and probable linkages need to be discussed. In fact, public good assumes the distribution of services equally to all members of the society which is problematic as it may not take care of equity issues in societies where some people suffer more and need special care and services. Public good is a 'troubled' notion which has its origin and also has been used in neo-classical and neoliberal approaches and it cannot be recommended without a proper understanding of the diverse ways in which the concept has been treated. The need for current claiming or reclaiming of such concepts started with environmental goods (although not many the so-called environmentalists realise it) to highlight destruction of global commons or resources which will result in loss of markets and therefore profits. The present reclaiming of the concept is also because of such a realisation as the pandemic has affected market interests. New approaches are evolving because of the socalled 'aid fatigue' of donors as they think that economic aids may be irrelevant at this time as the rich countries are also suffering and therefore, let them manage on their own!
Health as a public good is now reimagined as a form of governmentality by which the relation between health conditions, the actions which people take to ameliorate the conditions and institutions which aid such amelioration are reimagined to effect governing at a distance. ${ }^{3}$ It may strengthen global health governance but may eclipse the social determinants framework advanced to counter increasing influence of biomedical approaches on public health. In effect, the framework is an improvisation of the neo-classical approach in health where people do not matter but the ways of delivery become prominent. As Erikson says these kind of global conceptualisations can end up in 'faking global health' and as "global public health methods require designations of space, time and resources that are not innocent". ${ }^{4}$

The recent thrust on UHC also needs to be debated as among the three A's, only affordability seems to be given undue focus. This imbalanced focus is also not innocent as this helps suggesting insurance strategies to address affordability issues in health care which also helps in promoting privatization. According to World Health Organization (WHO), financial hardship should be central in UHC and all individuals and communities receive the full spectrum of essential, quality health services, from health promotion to prevention, treatment, rehabilitation, and palliative care.

The World Bank also supports UHC in order to provide quality, affordable health care as lack of it affects the longterm economic prospects of the countries. Such strategies as mentioned earlier will undermine the importance of primary health care and it is not enough to give passing 
references to such health-generating factors. The need for addressing equality issues including social determinants are also undermined in these fake global notions and their various compromised variants. Some earlier international policies such as health for all and health in all have also gone out of vogue. Some states in India and a few countries could grapple with the COVID pandemic at least initially largely due to the presence of a favourable socio-economic foundation in combination with health services factors as well as positive people-oriented decentralization. As long as the global health governance is not neutral and is a reflection of unequal power relations among countries and non-state actors under fluid partnerships and associations, there is bound to be questions raised on such global approaches and conceptualisations. ${ }^{5}$ They also have the danger of reducing health and health services into matters of governance and that too under the rubric of global governance.

\section{REFERENCES}

1. Abdalla SM, Maani N, Ettman CK, Galea S. Claiming Health as a Public Good in the PostCOVID-19 Era. Development (Rome). 2020;1-5.

2. Ghosh SM and Qadeer I. Public Good Perspective of Public Health. Evaluating Health systems Response to COVID-19. Economic and Political Weekly. 2020;55(36).

3. Bell K, Green J. On the perils of invoking neoliberalism in public health critique. Crit Public Health. 2016;26(3):239-43.

4. Erikson S. Faking global health. Crit Public Health. 2019;29(4):508-16.

5. Kruk ME. Globalisation and global health governance: Implications for public health. Global Public Health. 2012;7:54-62.

Cite this article as: Nayar RK. Global public good and universal health coverage: conceptual and practical concerns in the context of COVID-19. Int $\mathbf{J}$ Community Med Public Health 2021;8:3198-9. 